Int. J. Electrochem. Sci., 13 (2018) 4100 - 4114

\title{
Differential Pulse Stripping Voltammetric Determination of Metronidazole with Graphene-Sodium Dodecyl Sulfate Modified Carbon Paste Electrode
}

\author{
Mingfang Zhu ${ }^{1, *}$, Hongqing $\mathrm{Ye}^{1}$, Mushen Lai ${ }^{1}$, Jianshan Ye ${ }^{2}$, Jiemin Kuang ${ }^{1}$, Yuping Chen ${ }^{1}$, \\ Jingyue Wang ${ }^{l}$, Qianyi Mei ${ }^{1}$ \\ ${ }^{1}$ College of Pharmacy, Guangdong Pharmaceutical University, Guangzhou higher education mega \\ center, Guangzhou 510006, \\ ${ }^{2}$ School of Chemistry and Chemical Engineering, South China University of Technology, Wushan, \\ Guangzhou 510640, \\ *E-mail: zhumfgy@126.com
}

doi: $10.20964 / 2018.05 .73$

Received: 6 January 2018 / Accepted: 11 March 2018 / Published: 10 April 2018

\begin{abstract}
A sensitive electrochemical sensor using graphene self-assembled sodium dodecyl sulfate (SDS) as a composite membrane modified carbon paste electrode was developed for the detection of metronidazole (MNZ) using voltammetry. And the electrochemical properties of the composite membranes were studied by electrochemical impedance spectroscopy and chronocoulometry. At the optimum conditions, the concentration of MNZ was determined using oxidation peak by differential pulse stripping voltammetry (DPSV) in the linear range of 0.08 to $200 \mu \mathrm{M}$ with a detection limit of $8.5 \mathrm{nM}$. The high sensitivity, wider linear range, good reproducibility and the minimal surface fouling made the modified electrode suitable for determining MNZ concentrations in biological samples and tablets. Good recovery results were obtained.
\end{abstract}

Keywords: Metronidazole; Graphene; Sodium dodecyl sulfate; Modified carbon paste electrode; Voltammetry

\section{FULL TEXT}

(C) 2018 The Authors. Published by ESG (www.electrochemsci.org). This article is an open access article distributed under the terms and conditions of the Creative Commons Attribution license (http://creativecommons.org/licenses/by/4.0/). 